Perwira Journal of Science and Engineering (PJSE)

E-ISSN : 2775-8486

Volume 1 Nomor 1

Februari 2021

\title{
PENGARUH VARIASI WAKTU AGING PISTON SEPEDA MOTOR TOSSA SUPRA TERHADAP SIFAT KEKERASAN DAN STRUKTUR MIKRO
}

\author{
Nota Ali Sukarno ${ }^{1}$, Zakariyya Al Mufarid ${ }^{2}$ \\ 1,2 Universitas Perwira Purbalingga \\ Email: notalisukarno@unperba.ac.id
}

\begin{abstract}
Abstrak
Piston merupakan komponen utama pada kendaraan yang berfungsi mengubah energi kinetik menjadi energi gerak. Piston harus mampu bergerak bolak balik pada sebuah ruang bakar, juga harus mampu bergerak dengan cepat, yang berarti bahan piston harus ringan. Bahan yang baik dari piston adalah aluminium, tetapi bahan aluminium belumlah cukup, terutama bila menerima tekanan panas. Kemudian aluminium dicampur dengan paduan lain, misalnya magnesium, silikon dan sebagainya. Bahan ini disebut aluminium paduan. Pada penelitian kali ini bertujuan untuk mengetahui pengaruh variasi waktu aging terhadap kekerasan dan struktur mikro piston Tossa Supra dengan suhu treatment $500{ }^{\circ} \mathrm{C}$ selama 1 jam dan suhu aging $150{ }^{\circ} \mathrm{C}$ selama 2,3 , 4, dan 5 jam. Hasil uji kekerasan Brinnel menunjukkan kekerasan rata-rata Honda Supra lebih tinggi dibandingkan dengan piston Tossa supra yaitu $118 \mathrm{~kg} / \mathrm{mm}^{2}$ untuk Honda Supra dan $104 \mathrm{~kg} / \mathrm{mm}^{2}$ untuk Tossa Supra. Setelah piston Tossa supra mengalami aging dengan variasi waktu kekerannya meningkat yaitu selama 2 jam $113 \mathrm{~kg} / \mathrm{mm}^{2}, 3$ jam 114 $\mathrm{kg} / \mathrm{mm}^{2}, 4 \mathrm{jam} 118 \mathrm{~kg} / \mathrm{mm}^{2}$, dan $5 \mathrm{jam} 122 \mathrm{~kg} / \mathrm{mm}^{2}$. Sedangkan hasil dari pengamatan struktur mikro, diperoleh bahwa unsur paduan silikon dan magnesium pada piston Honda Supra lebih banyak, besar dan merata dibanding piston Tossa Supra. Oleh sebab itu, piston Honda Supra kekerasannya lebih tinggi, tetapi untuk piston Tossa Supra setelah mengalami aging unsur paduannya mengalami pula perubahan menjadi kelompok fasa $\mathrm{Mg}_{2} \mathrm{Si}$ yang besar dan merata.
\end{abstract}

Kata Kunci : Piston ; Aging ; Stuktur Mikro ; Kekerasan Brinnel

\section{Pendahuluan}

Pada industri otomotif, pesawat terbang pemakaian aluminium meningkat seiring jumlah kendaraan bermotor yang semakin meningkat di indonesia [1], [2], [3]. Industri Otomotif terutama komponennya adalah salah satu tujuan komersial untuk paduan aluminium silikon cor [4]. Komponen utama pada kendaraan bermotor salah satunya adalah piston. Selama mesin hidup, piston mengalami beban yang besar [5]. Menerima tekanan dan meneruskanya, melalui batang piston untuk memutar poros engkol adalah salah satu fungsi dari sebuah piston pada motor bakar [6]. Material paduan Al-Si adalah material yang mempunyai karakteristik kekerasan dan kekuatan yang tinggi, ringan, dan tahan korosi, yang merupakan material paduan pembuat piston. Akan tetapi akan ada beberapa sifat mekanik yang mengalami penurunan setelah mengalami kerusakan yang diakibat overheating [7]. Untuk meningkatkan kekuatan suatu paduan logam, salah satu caranya adalah melalui heat treatment atau perlakuan panas [3]. Perlakuan panas adalah metode yang banyak digunakan untuk meningkatkan sifat mekanik dari berbagai material termasuk paduan alumunium [4], disamping meningkatkan kekerasan juga meningkatkan kekuatan dan konduktifitasnya [8]. Pada proses perlakuan panas ini juga sangat baik untuk meningkatkan sifat mekanis dari paduan aluminium cor [9]. Tetapi paduan alumunium juga sangat rentan pada panas yang terlalu tinggi yang dapat menyebabkan retak [10]. 
Perwira Journal of Science and Engineering (PJSE)

E-ISSN : 2775-8486

Volume 1 Nomor 1

Februari 2021

Penelitian kali ini adalah membandingkan komponen sepeda motor yaitu piston sepeda motor Tossa Supra dengan perlakuan variasi waktu aging dan piston sepeda motor Honda Supra tanpa perlakuan. Adapun tujuan dari penelitian ini adalah untuk mengetahui pengaruh waktu aging terhadap struktur mikro dan kekerasan piston sepeda motor Tossa Supra agar mendekati struktur mikro dan kekerasan piston sepeda motor Honda Supra, dengan suhu treatment $500{ }^{\circ} \mathrm{C}$ selama 1 jam kemudian di aging pada suhu $150^{\circ} \mathrm{C}$, dengan waktu tahan $2,3,4$, dan 5 jam.

\section{Metode Penelitian}

Pada penelitian ini, metode yang digunakan adalah dengan melakukan uji kekerasan dengan menggunakan alat uji Brinnel dan struktur mikro dengan alat uji struktur mikro. Bahan uji yang digunakan adalah material piston sepeda motor Supra (baru) produk Tossa dan piston sepeda motor Supra (baru) produk Honda.

Untuk langkah-langkah pengujian terlebih dahulu material piston Tossa Supra dan piston Honda Supra dipotong sesuai keperluan uji kekerasan dan uji struktur mikro. Setelah material uji dipotong sesuai sampel benda uji, kemudian benda uji tersebut dilakukan mounting press agar benda uji memiliki dasar yang rata. Proses selanjutnya adalah pengamplasan dengan menggunakan amplas nomor 180, 400, 600, dan 1000 mesh, setalah pengamplasan, dilakukan penetesan cairan etsa pada benda uji dan dibiarkan selama 30 detik. Kemudian bersihkan cairan etsa tersebut dengan menggunakan air sabun dan keringkan dengan hair dryer. Setelah semua bahan uji selesai dipersiapkan, langkah selanjutnya adalah pengujian kekerasan dan srtuktur mikro dengan alat uji.

Adapun diagram alir penelitian dapat ditunjukkan pada gambar berikut ini :

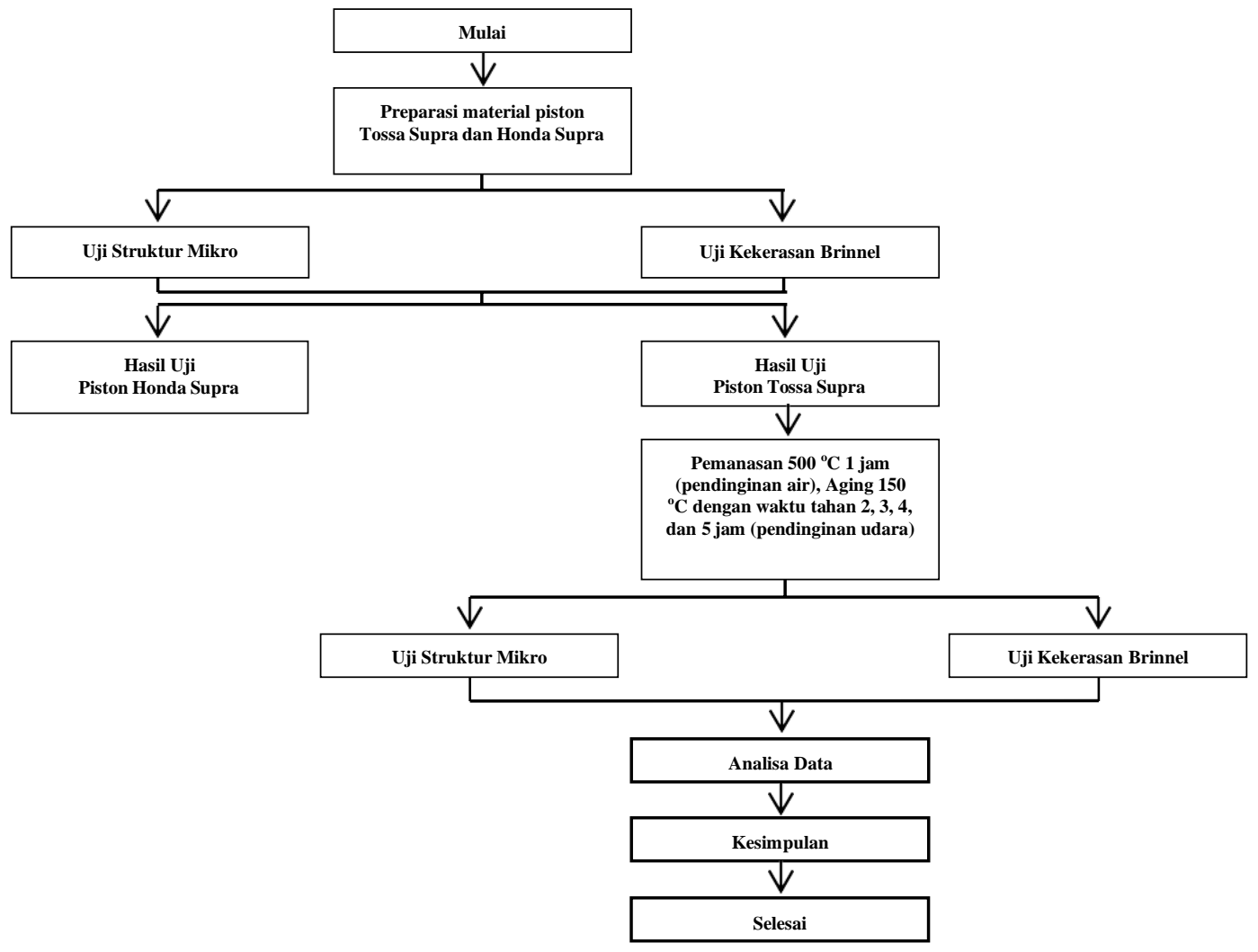

Gambar 1. Skema Diagram Alir Penelitian 
Perwira Journal of Science and Engineering (PJSE)

E-ISSN : 2775-8486

Volume 1 Nomor 1

Februari 2021

\section{Hasil dan Pembahasan}

\subsection{Hasil Pengujian Kekerasan}

Pada penelitian ini dilakukan pengujian kekerasan terhadap benda uji yaitu dua buah piston : piston Honda Supra dan Tossa supra dengan 4 variasi waktu aging, dengan spesifikasi sebagai berikut :

1. Piston Honda Supra tanpa perlakuan;

2. Piston Tossa Supra tanpa perlakuan;

3. Piston Tossa supra dengan proses aging 2 jam;

4. Piston Tossa supra dengan proses aging 3 jam;

5. Piston Tossa supra dengan proses aging 4 jam;

6. Piston Tossa supra dengan proses aging 5 jam;

Dengan masing-masing suhu treatment $500{ }^{\circ} \mathrm{C}$, waktu 1 jam dan suhu aging $150{ }^{\circ} \mathrm{C}$ dengan waktu tahan tersebut diatas.

Pada pengujian kekerasan ini masing-masing benda uji dilakukan sebanyak 3 kali dengan menggunakan pembebanan $62,5 \mathrm{kgf}$, diameter penetrator $2,5 \mathrm{~mm}$.

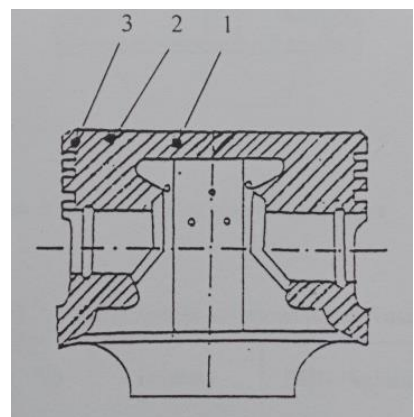

Gambar 2. Letak titik uji piston Honda Supra dan Tossa Supra

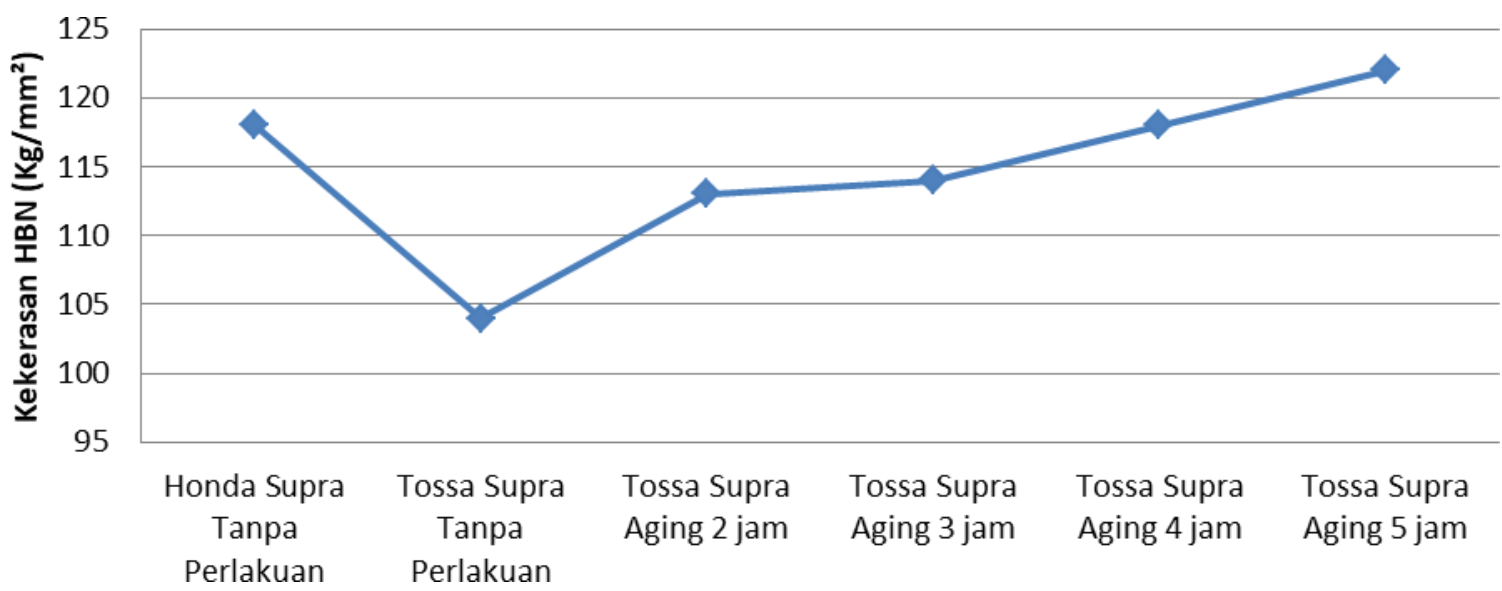

Gambar 3. Grafik perubahan kekerasan piston Honda Supra dan Tossa Supra

\subsection{Hasil Pengujian SEM/EDX}

Pada pengujian struktur mikro, dilakukan dengan pengamatan benda uji pada salah satu daerahbenda uji. Pengamatan struktur mikro ini menggunakan mikroskop 
Perwira Journal of Science and Engineering (PJSE)

E-ISSN : 2775-8486

Volume 1 Nomor 1

Februari 2021

optik setelah benda uji diestsa pada larutan $\mathrm{NaOH}(5 \% \mathrm{NaOH}+95 \%$ Air $)$, dengan pembesaran 500 kali.

Adapun hasil dari pengamatan tersebut adalah :

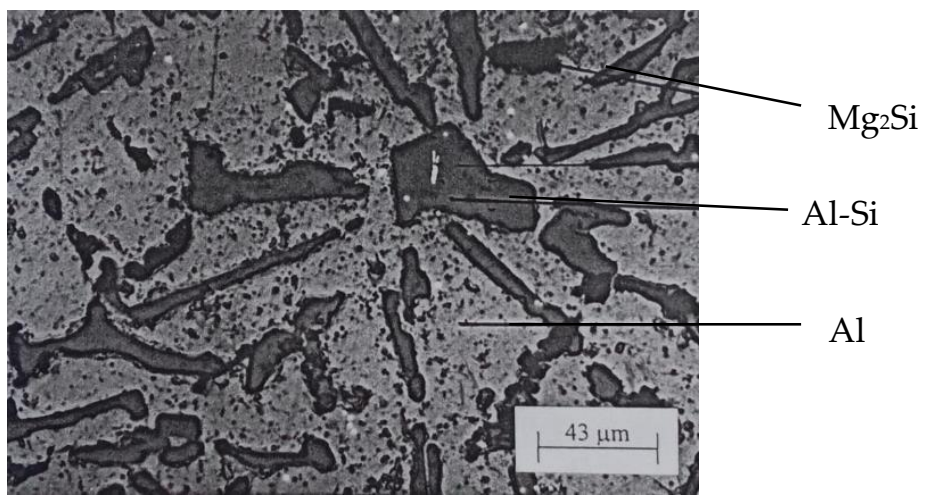

Gambar 4. Struktur mikro piston Honda Supra tanpa perlakuan

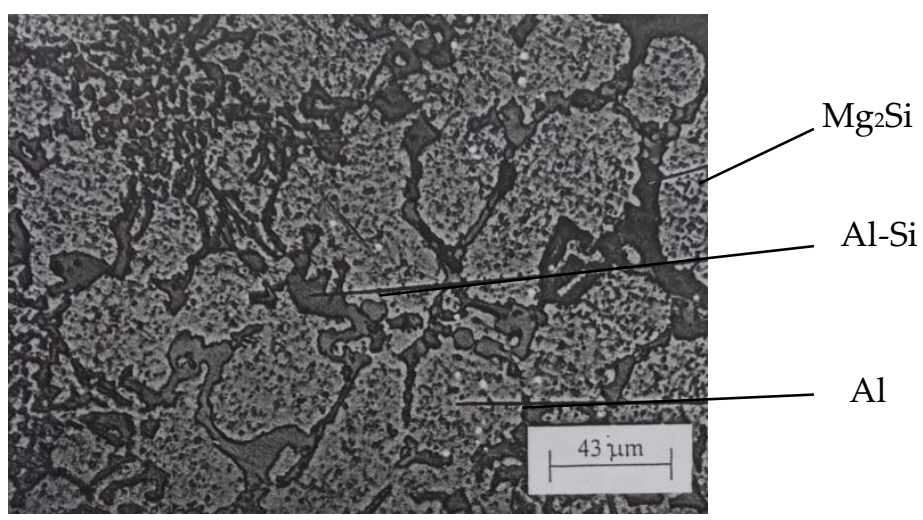

Gambar 5. Struktur mikro piston Tossa Supra tanpa perlakuan

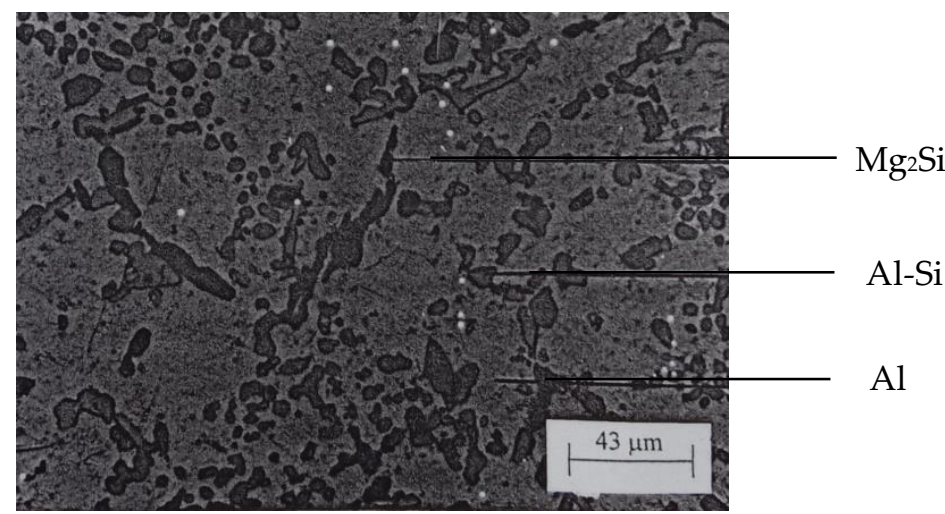

Gambar 6. Struktur mikro piston Tossa Supra suhu treatment $500{ }^{\circ} \mathrm{C}$, aging $150{ }^{\circ} \mathrm{C}$ Dengan waktu 2 jam 
Perwira Journal of Science and Engineering (PJSE)

E-ISSN : 2775-8486

Volume 1 Nomor 1

Februari 2021

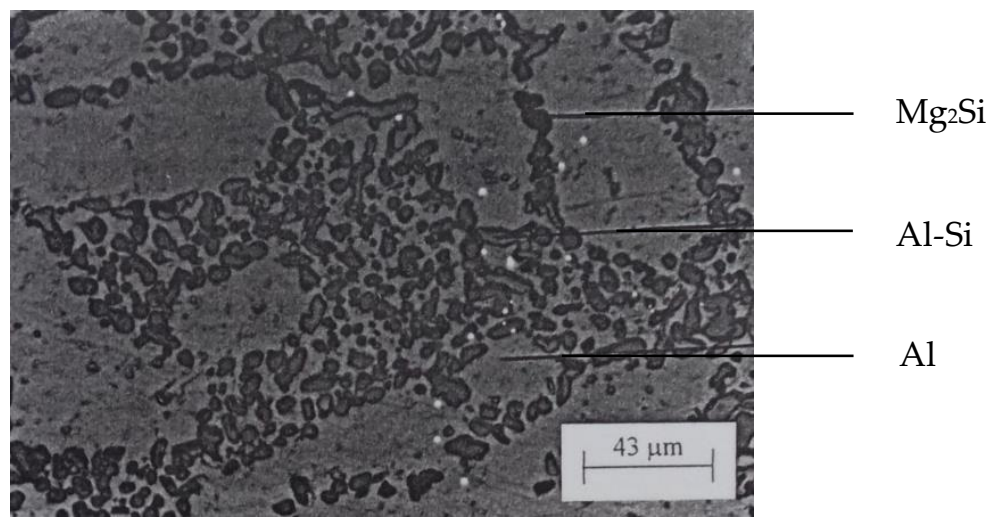

Gambar 7. Struktur mikro piston Tossa Supra suhu treatment $500{ }^{\circ} \mathrm{C}$, aging $150{ }^{\circ} \mathrm{C}$ Dengan waktu 3 jam

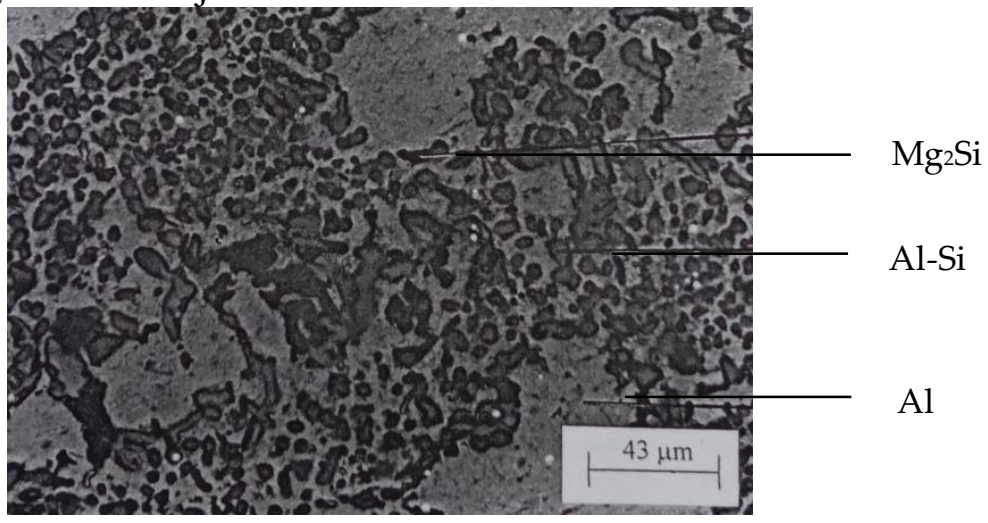

Gambar 8. Struktur mikro piston Tossa Supra suhu treatment $500{ }^{\circ} \mathrm{C}$, aging $150{ }^{\circ} \mathrm{C}$ Dengan waktu 4 jam

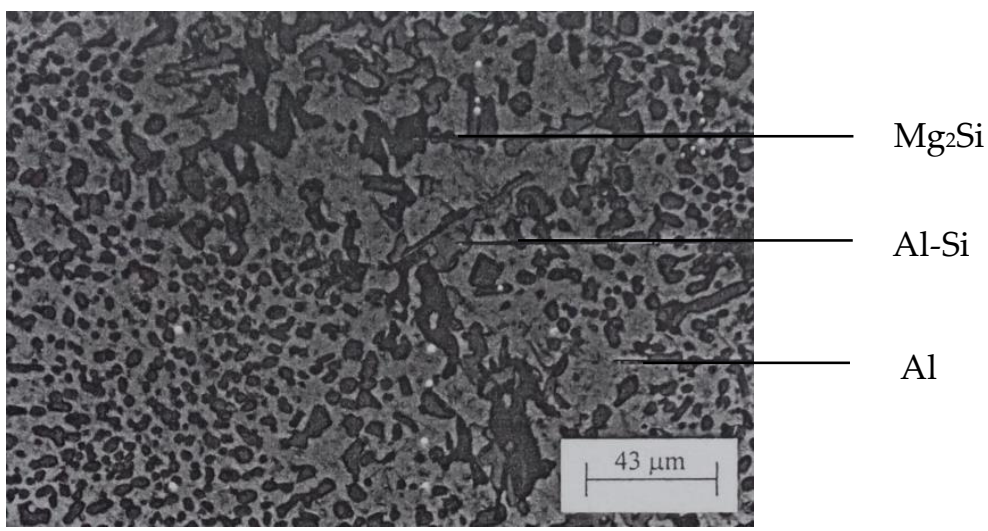

Gambar 9. Struktur mikro piston Tossa Supra suhu treatment $500{ }^{\circ} \mathrm{C}$, aging $150{ }^{\circ} \mathrm{C}$ Dengan waktu 5 jam

\subsection{Analisa Hasil Pengujian Kekerasan dan Struktur Mikro}

Dari nilai kekerasan rata-rata antar piston Honda Supra dan Tossa Supra pada gambar 3. sebelum mengalami perlakuan, nilai kekerasan piston Honda Supra lebih tinggi dari piston Tossa Supra, yaitu 118 kg/mm2 untuk Honda Supra dan 104 kg/mm2 utnuk Tossa supra. Setelah piston Tossa Supra mengalami perlakuan aging dengan empat variasi waktu, terlihat kekerasannya meningkat, yaitu pada 2 jam $113 \mathrm{~kg} / \mathrm{mm} 2,3$ jam $114 \mathrm{~kg} / \mathrm{mm} 2$, pada 4 jam $118 \mathrm{~kg} / \mathrm{mm} 2$ menyamai kekerasan pada piston Honda 
Perwira Journal of Science and Engineering (PJSE)

E-ISSN : 2775-8486

Volume 1 Nomor 1

Februari 2021

Supra tanpa perlakuan dan 5 jam $122 \mathrm{~kg} / \mathrm{mm} 2$ kekerasannya melebihi dari kekerasan piston Honda Supra.

Peningkatan kekerasan pada piston Tossa supra setelah mengalami aging dengan variasi waktu dikarenakan adanya perubahan struktur mikro yang terkandung pada piston tersebut seperti Si. Pada saat sebelum di aging paduan tersebut masih menyebar, akan tetapi pada saat dilakukan aging dari waktu 2 jam sampai dengan 5 jam, perubahan terjadi dengan adanya kelomok-kelompok yang kecil menjadi besar.

Dari pengamatan foto struktur mikro tanpa perlakuan, piston Honda Supra (gambar 4) mengandung lebih banyak $\mathrm{Si}$ dan $\mathrm{Mg}$ yang merata sehingga mempunyai kekerasan yang tinggi,sedangkan piston Tossa Supra (gambar 5) strukturnya lebih sedikit dan tida merata yang memungkinkan kekerasannya rendah.

Setelah piston Tossa Supra mengalami perlakuan aging, struktur mikronya sudah mulai berubah. Seperti terlihat pada gambar 7 sampai dengan gambar 10, aging 2 jam butiran paduannya sudah terlihat akan mengelompok, aging 3 jam sudah membentuk kelompok kecil, aging 4 jam terbentuk kelompok besar dan merata, membuat kekerasannya menyamai piston Honda Supra tanpa perlakuan yaitu $118 \mathrm{~kg} / \mathrm{mm}^{2}$ dan setelah aging 5 jam butirannya hampir menyeluruh terdapat pada permukaan yang menjadikannya lebih keras dari piston Honda Supra sebesar $122 \mathrm{~kg} / \mathrm{mm}^{2}$. Hal ini dikarenakan pada aluminium jika mengalami waktu aging yang lama akan menjadikan kekerasannya meningkat [8].

\section{Kesimpulan}

1. Dari nilai kekerasan rata-rata antar piston Honda Supra dan Tossa Supra pada gambar 4. sebelum mengalami perlakuan, nilai kekerasan piston Honda Supra lebih tinggi dari piston Tossa Supra, yaitu $118 \mathrm{~kg} / \mathrm{mm} 2$ untuk Honda Supra dan $104 \mathrm{~kg} / \mathrm{mm} 2$ utnuk Tossa supra.

2. Nilai kekerasan piston Tossa Supra dapat menyamai nilai kekerasan piston Honda Supra setelah mengalami waktu aging 4 jam, suhu $150{ }^{\circ} \mathrm{C}$ dengan nikali kekerasan $118 \mathrm{~kg} / \mathrm{mm}^{2}$.

3. Struktur mikro piston Tossa Supra mengalami perubahan setelah mengalami perlakuan waktu aging, yaitu aging 2 jam butiran paduannya sudah terlihat akan mengelompok, aging 3 jam sudah membentuk kelompok kecil, aging 4 jam terbentuk kelompok besar dan merata, membuat kekerasannya menyamai piston Honda Supra tanpa perlakuan yaitu $118 \mathrm{~kg} / \mathrm{mm}^{2}$ dan setelah aging 5 jam butirannya hampir menyeluruh terdapat pada permukaan yang menjadikannya lebih keras dari piston Honda Supra sebesar $122 \mathrm{~kg} / \mathrm{mm}^{2}$. Hal ini dikarenakan pada aluminium jika mengalami waktu aging yang lama akan menjadikan kekerasannya meningkat.

\section{Referensi}

[1] F. ABDILLAH, "Perlakuan Panas Paduan Al-Si Pada Prototipe Piston Berbasis Material Piston Bekas,” 2010.

[2] P. Liu et al., "Effect of aging treatment on microstructure and corrosion behavior of $\mathrm{Al}-\mathrm{Zn}-\mathrm{Mg}$ aluminum alloy in aqueous solutions with different aggressive ions," J. Mater. Sci. Technol., vol. 64, pp. 85-98, 2021, doi: 10.1016/j.jmst.2019.09.030.

[3] B. Junipitoyo, M. F. Anfasa, L. Winiasri, and P. P. Surabaya, "Pengaruh Variasi 
Perwira Journal of Science and Engineering (PJSE)

E-ISSN : 2775-8486

Volume 1 Nomor 1

Februari 2021

Suhu Dan Waktu Heat Treatment Pada Aluminium Alloy 2024-T3 Terhadap Sifat Fisis Dan Mekanis Dengan Media," vol. 5, no. 2, pp. 38-47, 2020.

[4] K. Rashnoo, M. J. Sharifi, M. Azadi, and M. Azadi, "Influences of reinforcement and displacement rate on microstructure, mechanical properties and fracture behaviors of cylinder-head aluminum alloy," Mater. Chem. Phys., vol. 255, p. 123441, 2020, doi: 10.1016/j.matchemphys.2020.123441.

[5] R. B. S. Majanasastra, "Pengaruh Variable Waktu ( Aging Heat Treatment ) Terhadap Peningkatan Kekerasan Permukaan Dan Struktur Mikro," vol. 3, no. 2, pp. 87-101, 2015.

[6] S. Muhammad Rifai1, Nely Ana Mufarida, ST., M.T2., Andik Irawan, "PENGARUH KONTRUKSI PISTON STANDAR DAN PISTON DOME BERBAHAN BAKAR CAMPURAN PREMIUM DAN METHANOL TERHADAP PERFORMA MOTOR BAKAR 4 LANGKAH 110CC," 日本水産学会誌, vol. 35, no. 8, pp. 791-792, 1969, doi: 10.2331/suisan.35.791.

[7] Ad. S. Purnomo, "STUDI KOMPARASI KARAKTERISTIK PISTON SEPEDA MOTOR 4 TAK DAN 2 TAK," pp. 1-242, 2015.

[8] A. Z. Sultan, A. Tangkemanda, I. A. Djafar, and R. T. Rantepadang, "Pengaruh Perlakuan Panas Terhadap Sifat Mekanis dan Struktur Mikro Paduan Alumunium Silikon," J. Tek. Mesin Sinergi, vol. 17, no. 2, p. 206, 2020, doi: 10.31963/sinergi.v17i2.2083.

[9] S. Mizhar, "Pengaruh Heat Treatment Terhadap Struktur Mikro dan Kekerasan Aluminium Paduan Al-Si-Cu Pada Cylinder Head Sepeda Motor," vol. 3, no. 1, pp. 9-15, 2016.

[10] K. Sri Ram Vikas, V. S. N. V. Ramanab, R. Mohammedc, G. M. Reddyd, and K. S. Raoe, "Influence of post weld heat treatment on microstructure and pitting corrosion behavior of dissimilar Aluminium alloy friction," Mater. Today Proc., vol. 15, pp. 109-118, 2019, doi: 10.1016/j.matpr.2019.05.032. 